Case Report

\title{
Obstructive Small Bowel Metastasis from Uterine Leiomyosarcoma: A Case Report
}

\author{
Mutahir A. Tunio, ${ }^{1}$ Mushabbab AlAsiri, ${ }^{2}$ Rasha M. Saleh, ${ }^{3}$ Shomaila Amir Akbar, ${ }^{4}$ \\ Nagoud M. Ali, ${ }^{5}$ and Mohamed Abdalazez Senosy Hassan ${ }^{6}$ \\ ${ }^{1}$ Radiation Oncology, King Fahad Medical City, Riyadh, Saudi Arabia \\ ${ }^{2}$ Radiation Oncology, Comprehensive Cancer Center, King Fahad Medical City, Riyadh 59046, Saudi Arabia \\ ${ }^{3}$ Medical Oncology, Comprehensive Cancer Center, King Fahad Medical City, Riyadh 59046, Saudi Arabia \\ ${ }^{4}$ Radiation Oncology, King Fahad Medical City, Riyadh 59046, Saudi Arabia \\ ${ }^{5}$ Anatomic Pathology, King Fahad Medical City, Riyadh 11525, Saudi Arabia \\ ${ }^{6}$ Clinical Oncology, Minia Oncology Center, Minia, Egypt
}

Correspondence should be addressed to Mutahir A. Tunio; mkhairuddin@kfmc.med.sa

Received 4 December 2013; Accepted 15 January 2014; Published 4 March 2014

Academic Editors: C. S. Hsu and C.-C. Liang

Copyright (C) 2014 Mutahir A. Tunio et al. This is an open access article distributed under the Creative Commons Attribution License, which permits unrestricted use, distribution, and reproduction in any medium, provided the original work is properly cited.

\begin{abstract}
Background. Uterine leiomyosarcoma is a rare and aggressive gynecologic malignancy with an overall poor prognosis. Lungs, bones, and brain are common sites of metastases of uterine leiomyosarcoma. Metastases of uterine leiomyosarcoma to the small bowel are extremely rare, and only four case reports have been published to date. Case presentation. A 55-year-old Saudi woman diagnosed with a case of uterine leiomyosarcoma treated with total abdominal hysterectomy (TAH) and bilateral salpingooophorectomy (BSO) presented in emergency room after sixteen months with acute abdomen. Subsequent work-up showed a jejunal mass for which resection and end-to-end anastomosis were performed. Biopsy confirmed the diagnosis of small bowel metastasis from uterine leiomyosarcoma. Further staging work-up showed wide spread metastasis in lungs and brain. After palliative cranial irradiation, systemic chemotherapy based on single agent doxorubicin was started. Conclusion. Metastatic leiomyosarcoma of small bowel from uterine leiomyosarcoma is a rare entity and is sign of advanced disease. It should be differentiated from primary leiomyosarcoma of small bowel as both are treated with different systemic chemotherapeutic agents.
\end{abstract}

\section{Introduction}

Uterine leiomyosarcoma accounts for $3 \%$ of all uterine malignancies and it metastasize through hematogenous dissemination to the lungs, liver, bones, and the brain [1]. Small bowel is an extremely rare site of metastasis from uterine leiomyosarcoma $[2,3]$. Leiomyosarcoma of the small bowel can either be primary or secondary. Primary leiomyosarcomas arise from the muscularis propria layer of the intestinal wall and show immunopositivity DC117, CD34, and CK AE1/AE3. In contrary, secondary leiomyosarcomas arise from the mucosal layer of the intestinal wall and are negative for DC117, CD34, and CK AE1/AE3 [4]. Uterine leiomyosarcoma can invade small bowel by direct extension, hematogenous route, implantation, or via lymphatic route [5]. Acute abdomen (small bowel obstruction or perforation) secondary to metastatic uterine leiomyosarcoma to small bowel is not well known and has been documented by only four case reports till date [6]. Small bowel metastasis in uterine leiomyosarcoma is usually a sign of extensive disease and poor prognosis.

Herein we report a case of a 55-year-old Saudi women who presented in emergency room with acute abdomen secondary to small bowel metastasis from uterine leiomyosarcoma. 


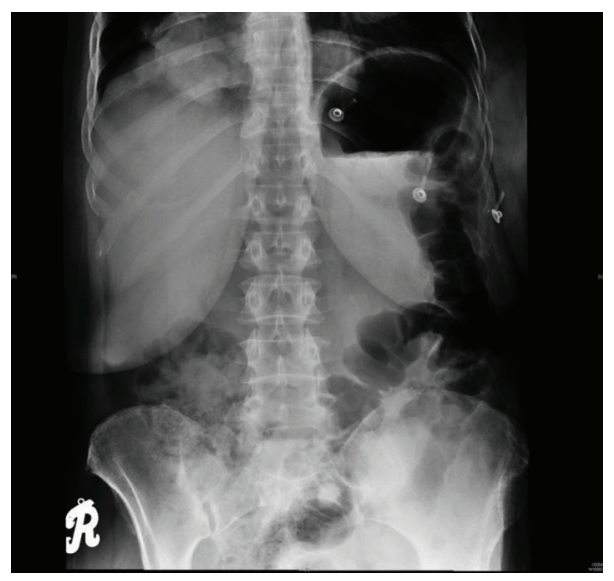

FIGURE 1: Plain abdominal radiograph showing dilatation of small bowel without any gas-fluid levels.

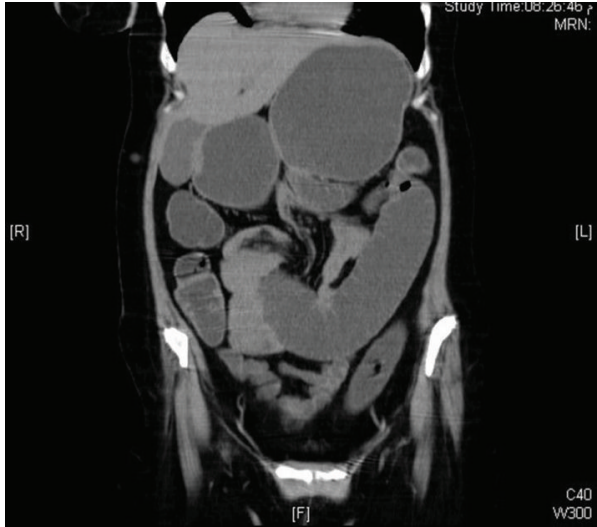

(a)

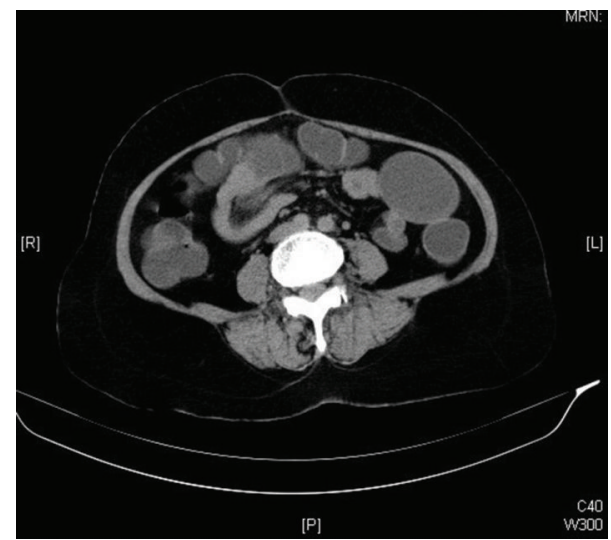

(b)

FIGURE 2: Computed tomography (CT) abdomen without contrast showing (a) coronal view: distended stomach, proximal small bowel loops extending down to midabdominal level where there was abrupt change in caliber of the bowel, and collapse of distal small bowel loops and (b) axial view: a soft tissue density lesion containing vessels.

\section{Case Presentation}

A 55-year-old Saudi woman was admitted to the Emergency Department with a chief complaint of episodes of paroxysmal abdominal pain. The pain started two weeks previously that was aggravated for the last two days with nausea, vomiting, and constipation. Past medical and surgical history revealed that she was diabetic since last 12 years and was on oral metformin $500 \mathrm{mg}$ three times a day and she underwent total abdominal hysterectomy (TAH) and bilateral salpingooophorectomy (BSO) sixteen months back for uterine leiomyosarcoma outside of our hospital without any adjuvant treatment.

During physical examination, moderate tenderness over the right epigastric and hypochondrial areas and active bowel sounds were observed. Plain abdominal X-ray showed dilatation of small bowel without any gas-fluid levels; Figure 1. Baseline hematology showed leukocytosis $\left(12.4 \times 10^{9} / \mathrm{L}\right)$, high absolute neutrophil count $\left(10.4 \times 10^{9} / \mathrm{L}\right)$, and normal hemoglobin and platelets counts. Serum chemistry showed lactate dehydrogenase (LDH) was $237 \mathrm{U} / \mathrm{L} \uparrow$ (normal: 135214), sodium $132 \mathrm{mmoL} / \mathrm{L} \downarrow$ (normal: 135-145), serum creatinine was $226 \mu \mathrm{moL} / \mathrm{L} \uparrow$ (normal: $44-80$ ), urea $15.1 \mathrm{mmoL} / \mathrm{L}$ $\uparrow$ (normal: 2.5-6.4), anion gap was $31.2 \mathrm{mmoL} / \mathrm{L}$ (normal: $12-$ 20), and lactate was $2.3 \mathrm{mmoL} / \mathrm{L}$ (normal: 1.1-2.2). Computed tomography (CT) abdomen without contrast showed distended stomach, proximal small bowel loops extending down to midabdominal level where there was abrupt change in caliber of the bowel, and collapse of distal small bowel loops. At this transition point appeared a soft tissue density containing vessels, which raised the possibility of intussusception with a lesion; Figure 2. Patient underwent exploratory laparotomy on the same day. During exploration, a jejunal mass of size $6 \mathrm{~cm}$ was found which was resected and anastomosis was performed. Histopathology of jejunal mass was leiomyosarcoma arising from mucosa. Further immunohistochemistry (IHC) favored jejunal mass as metastatic leiomyosarcoma rather than primary leiomyosarcoma (positivity for SMA and negativity for S100, DC117, CD34, and CK AE1/AE3); Figure 3. Further histopathological review of primary surgery 


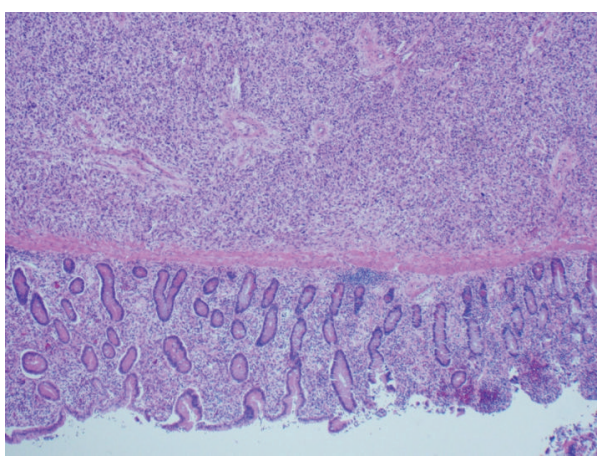

(a)

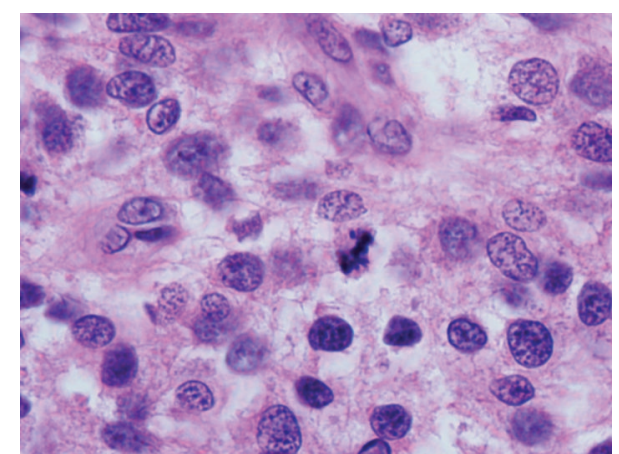

(b)

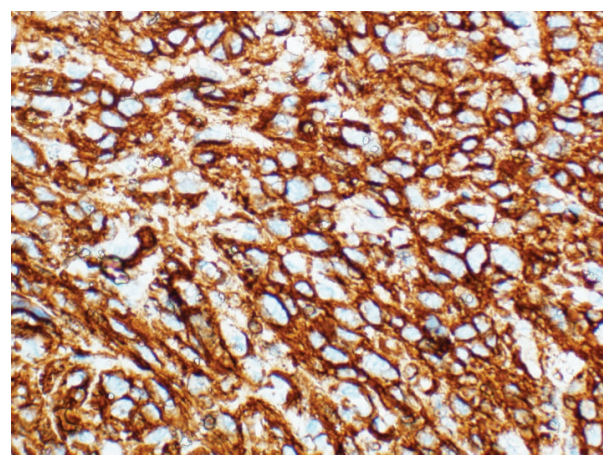

(c)

Figure 3: (a) Hematoxylin and Eosin staining $(\times 40)(b)(\times 100)$ of the tumor at the submucosa and muscular layer of the small bowel and showing (c) immunopositivity for SMA.

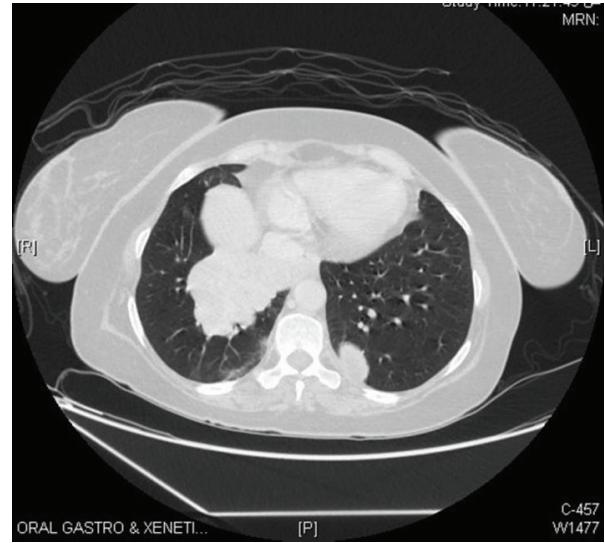

FIGURE 4: Computed tomography of chest showing largest pulmonary metastatic nodule of size $10 \times 6 \mathrm{~cm}$ in right middle and lower lobes invading adjacent mediastinum, mediastinal pleura, pericardium, and right pulmonary vein and bronchus.

specimen showed $7 \mathrm{~cm}$ uterine leiomyosarcoma involving out half of myometrium without any lymphovascular invasion (LVSI) which confirmed the diagnosis; Figure 4.

After her successful postoperative recovery, staging workup was done. Bone scintigraphy was found normal. CT chest showed multiple pulmonary metastatic nodules; largest one was of size $10 \times 6 \mathrm{~cm}$ in right middle and lower lobes

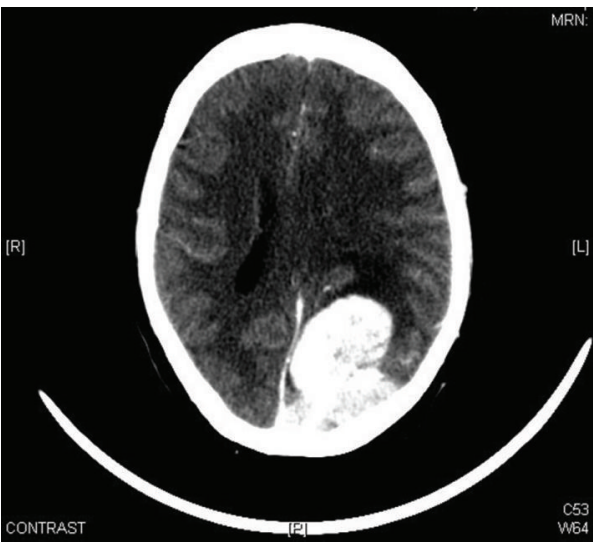

FIGURE 5: Computed tomography of brain showing multiple intraand extracranial enhancing lesions at left occipital, left parietal subdura $(5.6 \times 3.5 \mathrm{~cm})$ with midline shift and vasogenic edema, and right cerebellum.

invading adjacent mediastinum, mediastinal pleura, pericardium, and right pulmonary vein and bronchus; Figure 5 . CT brain revealed multiple intra- and extracranial enhancing lesions at left occipital, left parietal subdura $(5.6 \times 3.5 \mathrm{~cm})$ with midline shift and vasogenic edema, and right cerebellum. Also there was superior sagittal sinus tumoral thrombosis.

After discussing her case in multidisciplinary board meeting, she was given palliative cranial radiotherapy $20 \mathrm{~Gy}$ 
TABLE 1: Small bowel metastasis secondary to uterine leiomyosarcoma reported from 1993 to 2012.

\begin{tabular}{|c|c|c|c|c|c|c|}
\hline Author & $\begin{array}{l}\text { Age } \\
\text { years }\end{array}$ & $\begin{array}{c}\text { From time of initial } \\
\text { treatment }\end{array}$ & Location & $\begin{array}{c}\text { Other sites of } \\
\text { metastasis }\end{array}$ & Treatment & Survival \\
\hline Gerst et al. [2] & 56 & 8 years after TAH + BSO & $\begin{array}{l}\text { Ileoileal } \\
\text { junction }\end{array}$ & $\begin{array}{c}\text { Lungs } \\
\text { Liver } \\
\end{array}$ & $\begin{array}{c}\text { Surgical resection } \\
\text { chemotherapy }\end{array}$ & 24 months \\
\hline Ben-Ishay et al. [3] & 60 & 4 years after TAH + BSO & Jejunum & Not mentioned & Surgical resection & Not mentioned \\
\hline Sidani et al. [4] & 48 & 5 years after TAH + BSO & Ileum & Lungs & $\begin{array}{c}\text { Surgical resection } \\
\text { chemotherapy }\end{array}$ & Not mentioned \\
\hline Saylam et al. [6] & 59 & $\begin{array}{c}16 \text { months after } \mathrm{TAH}+ \\
\text { BSO }\end{array}$ & $\begin{array}{l}\text { Ileoileal } \\
\text { junction }\end{array}$ & Bones & Surgical resection & $\begin{array}{c}\text { Alive at } 10 \\
\text { months }\end{array}$ \\
\hline Present case & 57 & $\begin{array}{l}16 \text { months after TAH }+ \\
\text { BSO }\end{array}$ & Jejunum & $\begin{array}{l}\text { Lungs } \\
\text { Brain }\end{array}$ & $\begin{array}{c}\text { Surgical } \\
\text { resection, } \\
\text { radiotherapy, and } \\
\text { chemotherapy }\end{array}$ & Alive at 3 months \\
\hline
\end{tabular}

TAH + BSO: total abdominal hysterectomy and bilateral salpingooophorectomy.

in 5 fractions over a week and then she was started on systemic chemotherapy based on single agent doxorubicin $\left(60 \mathrm{mg} / \mathrm{m}^{2}\right)$.

At time of publication patient was found alive and was receiving chemotherapy.

\section{Discussion}

Small bowel metastases are uncommon and account for $10 \%$ of all small bowel tumors [7]. The most common sites of primary tumor metastasizing to small bowel are adenocarcinoma of uterus, cervix, colon, and lung; ductal carcinoma of breast; and melanoma [8]. Metastasis to small bowel by uterine leiomyosarcoma is an extremely rare manifestation and carries an unfavorable prognosis. Only four cases have been reported so far in the world literature; Table 1.

The mechanism of metastasis to the heart is not well known. Possible routes are direct extension, hematogenous route, implantation, or via lymphatic route. In our patient small bowel was affected through hematogenous pathway. Metastatic leiomyosarcoma shall be differentiated from rare primary intestinal leiomyosarcoma with help of IHC; both are treated with different chemotherapeutic agents [4]. Primary leiomyosarcomas are uncommon tumors that arise from the muscularis propria layer of the intestinal wall in contrary to metastatic leiomyosarcomas which are mostly of mucosal origin [9].

Metastatic small bowel leiomyosarcoma secondary to uterine leiomyosarcoma is considered a sign of advanced disease with high tumor burden as seen in our patient. Such patients have shown response to doxorubicin alone, gemcitabine alone, or gemcitabine plus docetaxel with median survival rates of 14.7 to 24 months [10].

In conclusion, small bowel metastasis following treatment for uterine leiomyosarcoma is rare. IHC helps to differentiate it from primary leiomyosarcoma of small bowel. Metastatic leiomyosarcoma is sign of advanced disease with grave prognosis and such patients may benefit from single agent doxorubicin-based systemic chemotherapy.

\section{Consent}

Written informed consent was taken from the patient for the publication of this case report.

\section{Conflict of Interests}

The authors have no potential conflict of interests and no grants or funds received for this case report.

\section{Authors' Contribution}

Mutahir A. Tunio and Mushabbab AlAsiri contributed to the concept of the study; Shomaila Amir Akbar, Rasha M. Saleh, Mushabbab AlAsiri, Mutahir A. Tunio, and Mohamed Abdalazez Senosy Hassan contributed to the research of the literature; Mutahir A. Tunio, Mohamed Abdalazez Senosy Hassan, and Shomaila Amir Akbar contributed by writing the paper; Nagoud M. Ali provided pathological assistance; and Mutahir A. Tunio, Mushabbab AlAsiri, Shomaila Amir Akbar, Rasha M. Saleh, Nagoud M. Ali, and Mohamed Abdalazez Senosy Hassan all approved the content of the paper.

\section{References}

[1] E. D'angelo and J. Prat, "Uterine sarcomas: a review," Gynecologic Oncology, vol. 116, no. 1, pp. 131-139, 2010.

[2] P. H. Gerst, J. Levy, K. Swaminathan, V. Kshettry, and E. Albu, "Metastatic leiomyosarcoma of the uterus: unusual presentation of a case with late endobronchial and small bowel metastases," Gynecologic Oncology, vol. 49, no. 2, pp. 271-275, 1993.

[3] O. Ben-Ishay, P. Shmulevsky, E. Brauner, E. Vladowsy, and Y. Kluger, "Mucosal small bowel metastasis from uterine leiomyosarcoma," Israel Medical Association Journal, vol. 12, no. 5, pp. 309-310, 2010.

[4] H. Sidani, J. Ezzedine, R. Zbibo, R. Jalloul, and M. Ramadan, "Metastases of leiomyosarcoma of the uterus localized in the small intestine," Journal de Chirurgie, vol. 133, no. 7, pp. 346347, 1996.

[5] R. C. Semelka, G. John, N. L. Kelekis, D. A. Burdeny, and S. M. Ascher, "Small bowel neoplastic disease: demonstration by 
MRI," Journal of Magnetic Resonance Imaging, vol. 6, no. 6, pp. 855-860, 1996.

[6] B. Saylam, O. V. Ozozan, A. P. Duzgun, B. Kulah, O. Han, and F. Coskun, "Perforated intestinal leiomyosarcoma as a metastasis of uterine leiomyosarcoma: a case report," Cases Journal, vol. 2, no. 9, article 9288, 2009.

[7] R. C. Dwivedi, R. Kazi, N. Agrawal et al., "Comprehensive review of small bowel metastasis from head and neck squamous cell carcinoma," Oral Oncology, vol. 46, no. 5, pp. 330-335, 2010.

[8] L. Lv, Y. Zhao, H. Liu, and Z. Peng, "Case report of small bowel obstruction caused by small intestinal metastasis of bilateral breast cancer," Experimental and Therapeutic Medicine, vol. 6, no. 3, pp. 675-678, 2013.

[9] J. M. Wilson, D. B. Melvin, G. F. Gray, and B. Thorbjarnarson, "Primary malignancies of the small bowel: a report of 96 cases and review of the literature," Annals of Surgery, vol. 180, no. 2, pp. 175-179, 1974.

[10] A. A. Gupta, X. Yao, S. Verma, H. Mackay, and L. Hopkins, "Chemotherapy (gemcitabine, docetaxel plus gemcitabine, doxorubicin, or trabectedin) in inoperable, locally advanced, recurrent, or metastatic uterine leiomyosarcoma: a clinical practice guideline," Current Oncology, vol. 20, no. 5, pp. 448-454, 2013. 


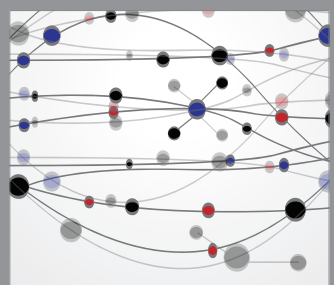

The Scientific World Journal
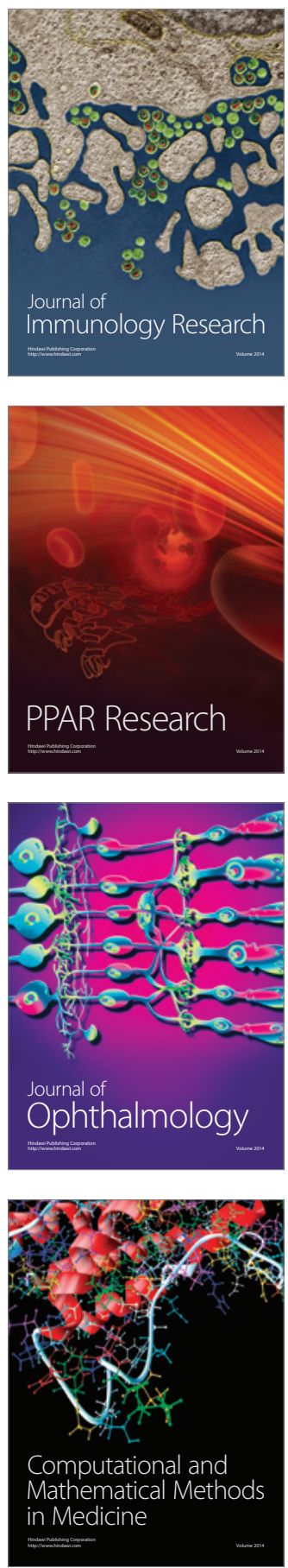

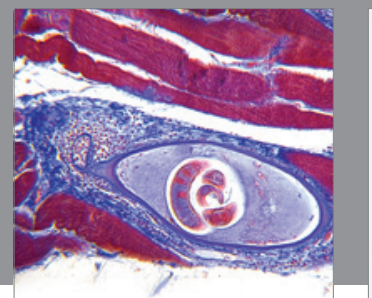

Gastroenterology

Research and Practice
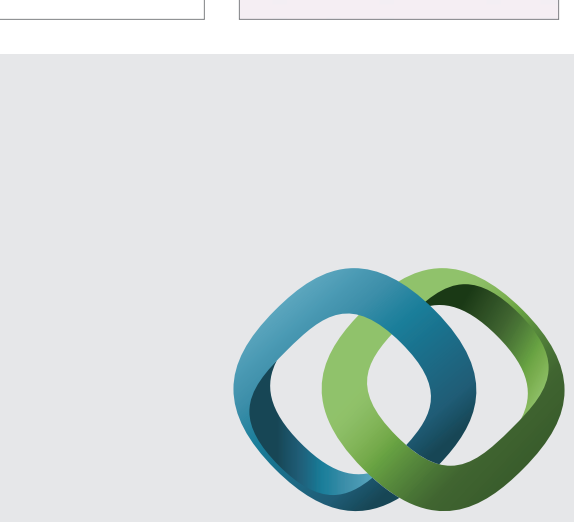

\section{Hindawi}

Submit your manuscripts at

http://www.hindawi.com
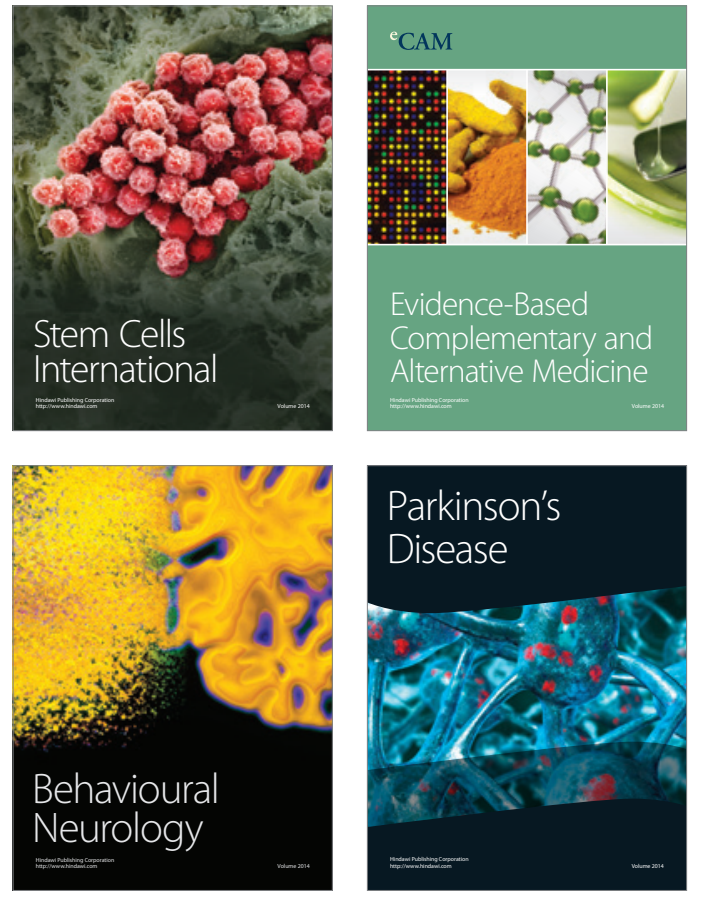
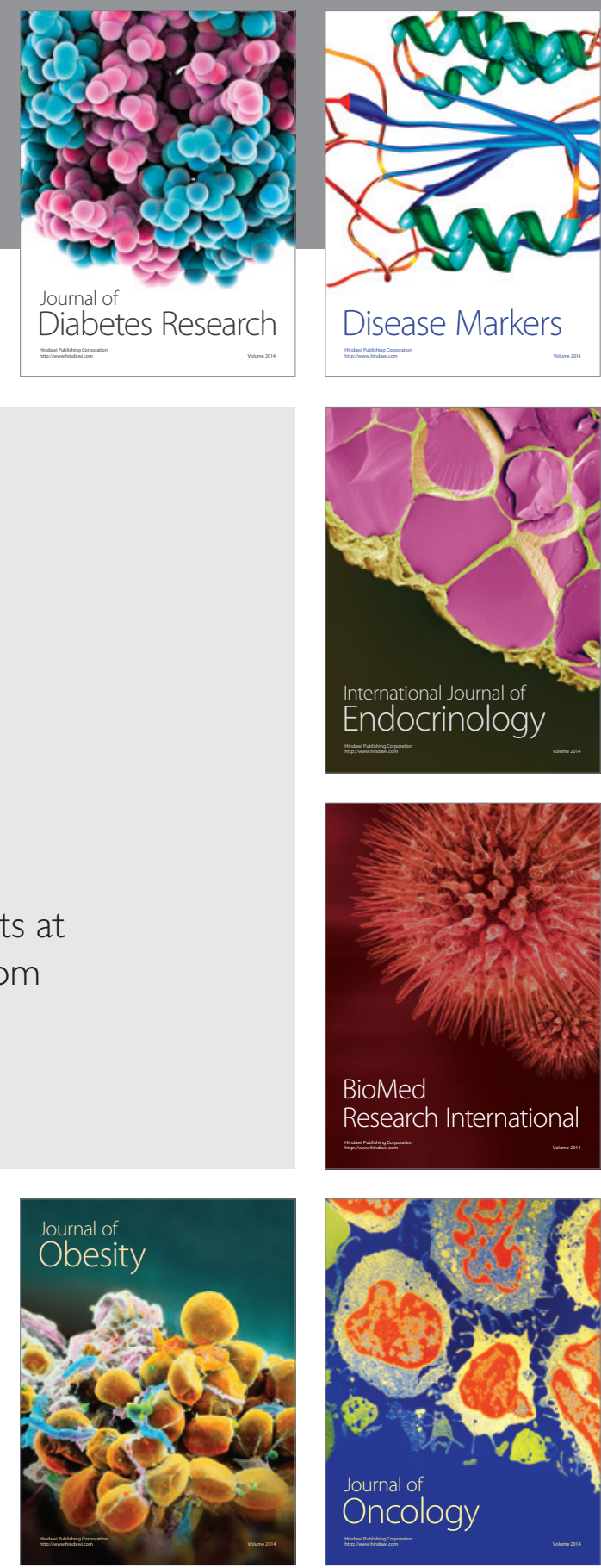

Disease Markers
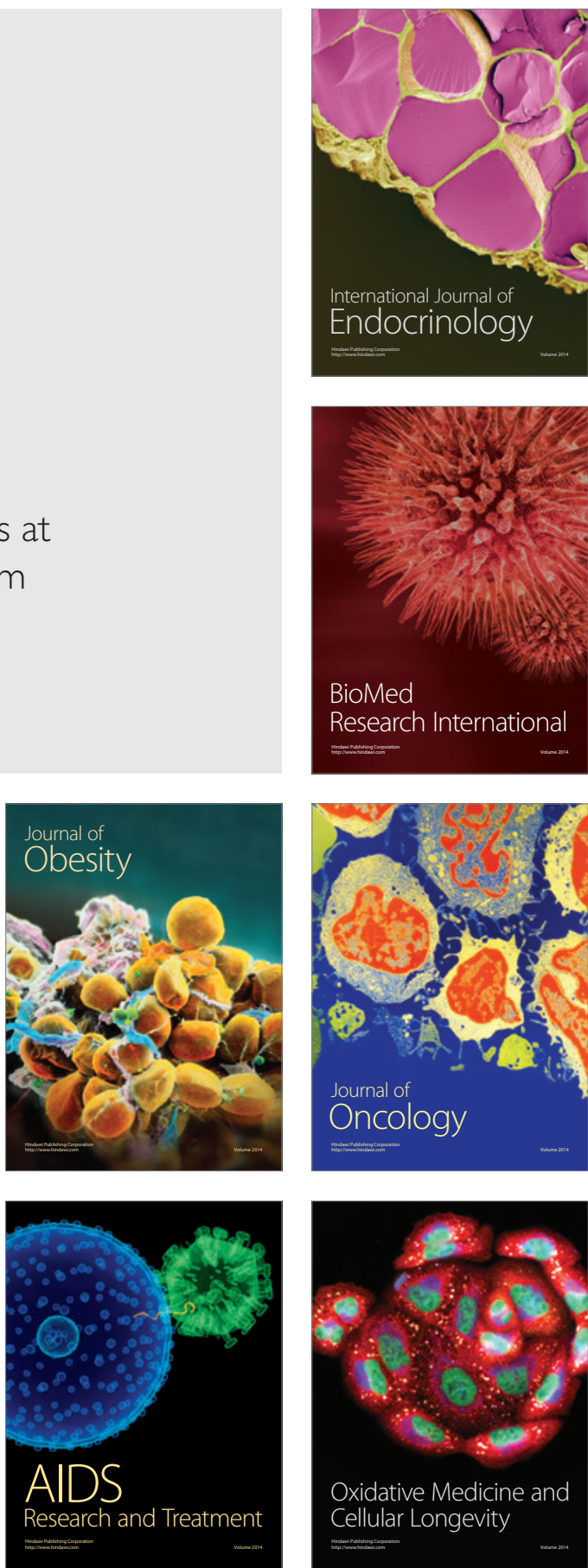